\title{
Changes in circulating adiponectin and tumour necrosis factor-a and their relationship with insulin resistance in periparturient dairy cows
}

\author{
Zafer Mecitoglu ${ }^{1}$, Sezgin Senturk ${ }^{1}$, Gulsah Akgul ${ }^{1}$, Duygu Udum ${ }^{2}$, \\ Ender Uzabac1 $^{3}$, Sevim Kasap ${ }^{1}$, Serkan Catik ${ }^{1}$ \\ ${ }^{1}$ Department of Internal Medicine, ${ }^{2}$ Department of Biochemistry, \\ ${ }^{3}$ Department of Biostatistics, \\ Faculty of Veterinary Medicine, Uludag University, 16059 Gorukle, Bursa, Turkey \\ sezsen@uludag.edu.tr
}

Received: December 11, 2015 Accepted: May 13, 2016

\begin{abstract}
Introduction: The aim of the study was to investigate changes in the serum levels of adiponectin and TNF- $\alpha$, as well as insulin sensitivity, and to elucidate the possible relationship among the parameters and negative energy balance during the periparturient period of dairy cows. Material and Methods: Thirty primiparous Holstein dairy cows were selected for the study. Blood samples were collected from each cow seven days before the expected calving date, on the calving day, and 7, 14, and 21 days after calving. Blood non-esterified fatty acids (NEFA), $\beta$-hydroxybutyric acid (BHBA), glucose, insulin, adiponectin, and TNF- $\alpha$ levels were measured. Revised Quantitative Insulin Sensitivity Check Index (rQUICKI) was calculated using data on NEFA, insulin, and glucose concentrations. Results: When compared to prepartum levels, serum concentration of adiponectin significantly increased on day 21 postpartum. The rQUICKI increased and NEFA levels decreased on day 7 after parturition. Insulin and glucose levels decreased on days 7, 14, and 21 postpartum when compared with prepartum levels. BHBA levels decreased on day 21 and TNF- $\alpha$ concentration also decreased on days 7, 14, and 21 postpartum. Adiponectin levels positively correlated with NEFA during the preparturient period. Negative correlation was detected between adiponectin and rQUICKI on calving day and on $14^{\text {th }}$ day after parturition. TNF- $\alpha$ concentration positively correlated with glucose levels on day 7 prepartum and on $21^{\text {st }}$ day postpartum and with rQUICKI on $21^{\text {st }}$ day postpartum. Negative correlation was detected between adiponectin level and insulin sensitivity. Conclusion: Based on the results of the study, we concluded that adiponectin could possibly increase insulin sensitivity when blood NEFA concentrations are elevated.
\end{abstract}

Keywords: cows, perinatal period, adiponectin, TNF- $\alpha$, insulin resistance.

\section{Introduction}

In early lactation, feed intake is not able to meet high energy demands of high-yielding dairy cows. Thus, most cattle suffer from negative energy balance (NEB), which is characterised by increased lypolysis and decreased lypogenesis rates, resulting in increased blood levels of $\beta$-hydroxybutyric acids (BHBA) and non-esterified fatty acids (NEFA) (6). Increased glucose demands in the mammary glands of postpartum dairy cows are believed to be fulfilled by whole body insulin resistance, excluding the mammary glands, which is observed since late pregnancy $(16,24)$. Insulin resistance is described as a state in which physiological level of insulin produces lesser than normal biological response (9). In diseases such as ketosis, fatty liver, and left displacement of the abomasum, low tissue responsiveness to insulin was detected and asserted as a pathogenic factor of the mentioned disorders $(6,21$, 23). The level of insulin resistance is generally measured by using different types of the glucose tolerance test (GTT); however, time constraints limit the usefulness of GTT for epidemiological studies with numerous study populations. As such, a more practical approach for evaluation of insulin resistance in cattle, called "revised Quantitative Insulin Sensitivity Check 
Index" (rQUICKI), was introduced by Holtenius and Holtenius (7). The rQUICKI is based on formulation of blood insulin, glucose, and NEFA levels.

Adiponectin and tumour necrosis factor- $\alpha$ (TNF- $\alpha)$ are closely related with insulin resistance $(11,12,29)$. Adiponectin is a hormone secreted mainly from adipose tissue, which improves insulin sensitivity by decreasing triglyceride content in muscles and the liver $(29,30)$. Komatsu et al. (10) reported that adiponectin plays an important role in insulin resistance in the adipose tissue and mammary gland of lactating cows. In contrast to the insulin-enhancing effects of adiponectin, TNF- $\alpha$ has insulin resistance-inducing effects (8). The relationship between serum TNF- $\alpha$ activity and insulin resistance was demonstrated in cows with fatty liver (19). Thus, in the presented study, we aimed to investigate changes in serum adiponectin, TNF- $\alpha$ levels, and insulin resistance, and to elucidate the possible relationship between the mentioned parameters and NEB in dairy cows during the periparturient period.

\section{Material and Methods}

Animals and sample collection. Primiparous Holstein dairy cows $(n=30)$ with an expected calving date within the next 7 days were selected for the study. All cows were from the same herd and yield group, and the management and feeding conditions were identical for all animals. Body condition scores (BSC) of the animals were assessed using a five-point scale and 0.25 increments by a single person as described by Ferguson et al. (4). Only cows with BCS between 3.25 and 3.75 were selected for the study. The mean milk production during the last lactation was $9560 \pm 65.8 \mathrm{~kg}$ (305 days) per cow. Blood samples from each cow were collected to plain tubes by jugular vein puncture on day 7 before the expected calving date, on the calving day, and 7 , 14, and 21 days after calving. Animals which calved more than 2 days earlier or later were not included in the study. Samples for NEFA analysis were collected before morning feeding. According to Eicher et al. (3), blood BHBA levels increase after feeding thus it is suggested to collect blood samples $4-5 \mathrm{~h}$ after feeding in order to determine peak concentration of BHBA. Therefore, blood samples for BHBA, glucose, insulin, adiponectin, and TNF- $\alpha$ analysis were collected $4-5 \mathrm{~h}$ after morning feeding between 10.00 and 11.00. On calving day, blood samples were collected after calving. After clotting, the samples were centrifuged at 3000 r.p.m. for $20 \mathrm{~min}$ and sera were immediately separated and stored at $-20^{\circ} \mathrm{C}$ until analyses which were done within one week after the last sample collection.

Biochemical analyses. Serum glucose was measured with the use of Roche Cobas Integra 400 (Roche Diagnostics, USA) via a hexokinase enzymatic reaction. Serum TNF- $\alpha$ (CSB-E 1202B, Cusabio
Biotech Co., China), NEFA (CK-E90284, Eastbiopharm, China), adiponectin (E90440, Eastbiopharm, China), insulin (CSB-E 11993B, Cusabio Biotech Co., China), and BHBA (CK-E9043, Eastbiopharm, China) levels were measured using commercial bovine ELISA kits (Ultra Microplate Reader, BIO-TEK Instruments, Epoch INC) according to manufacturers' instructions. Microsoft Excel programme was used to calculate the coefficient of variation $(\mathrm{CV})$ from ELISA results, and CV values were calculated to compare mean concentrations for the same samples. It was found that the value amounted to $6 \%$ in inter-assay variation on each plate. The rQUICKI was estimated according to Perseghin et al. (20), where rQUICKI $=1 /[\log ($ glucose, $\mathrm{mg} / \mathrm{dL})+\log$ (insulin, $\mu \mathrm{U} / \mathrm{mL})+\log (\mathrm{NEFA}, \mathrm{mmol} / \mathrm{L})]$.

Statistical analysis. Statistical analysis of the results was performed using Sigma Plot 12 software (Systat Software Inc., USA). Normality test was performed using Shapiro-Wilk test and the data were found to be normally distributed. Serum hormone, metabolite, and rQUICKI values between the days of the study were compared using repeated measures analysis of variance (RM ANOVA). Tukey test was performed for comparison between prepartum and postpartum levels of serum hormone, metabolite levels, and rQUICKI values. The relationship among adiponectin, TNF- $\alpha$, NEFA, insulin, glucose, and BHBA concentrations and rQUICKI calculations were quantified by Pearson's correlation coefficients. For all analyses, $\mathrm{P} \leq 0.05$ was considered significant.

\section{Results}

When compared to prepartum levels, serum adiponectin levels significantly increased on day 21 postpartum (Table 1). The rQUICKI increased and NEFA levels decreased on day seven after parturition (Table 1). Insulin and glucose levels decreased on days 7,14 , and 21 postpartum when compared with prepartum levels (Table 1). BHBA levels decreased on day 21 and TNF- $\alpha$ levels also decreased on days 7, 14, and 21 (Table 1).

Table 2 shows the correlations between the parameters evaluated in the present study. Adiponectin levels positively correlated with NEFA during the periparturient period. A negative correlation was detected between adiponectin and rQUICKI on calving day and on $14^{\text {th }}$ day after parturition. Similarly, a negative correlation between adiponectin and glucose levels was observed on day 7 prepartum and on day 21 postpartum, as well as between the concentrations of adiponectin and insulin on day 7 prepartum. Adiponectin and TNF- $\alpha$ negatively correlated in prepartum period and 21 days after parturition. A negative correlation between adiponectin and BHBA was found on $7^{\text {th }}$ day prepartum, whereas a positive correlation was noted 14 days after calving. The 
rQUICKI and BHBA levels were negatively correlated on days 7 and 14 postpartum. TNF- $\alpha$ was positively correlated with glucose on day 7 prepartum and on day 21 postpartum, and with rQUICKI on day 21 postpartum. BHBA and insulin levels were positively correlated during the entire investigated period. TNF- $\alpha$ was also positively correlated with glucose levels 7 days before and 21 days after parturition.

Table 1. Serum adiponectin $(\mu \mathrm{g} / \mathrm{mL})$, TNF- $\alpha(\mathrm{ng} / \mathrm{mL})$, NEFA (mmol/L), insulin (nIU/mL), glucose (mg/dL), and BHBA (mg/dL) concentrations, and rQUCKI during the periparturient period in cows $(n=30)$

\begin{tabular}{|c|c|c|c|c|c|}
\hline \multirow{2}{*}{ Parameter tested } & \multicolumn{5}{|c|}{ Days } \\
\hline & -7 & 0 (calving) & 7 & 14 & 21 \\
\hline Adiponectin & $16.79 \pm 1.16$ & $16.36 \pm 1.32$ & $17.16 \pm 0.81$ & $17.18 \pm 1.36$ & $20.15 \pm 1.45^{*}$ \\
\hline TNF- $\alpha$ & $0.61 \pm 0.11$ & $0.49 \pm 0.04$ & $0.33 \pm 0.02 *$ & $0.40 \pm 0.06^{*}$ & $0.29 \pm 0.09^{*}$ \\
\hline rQUICKI & $0.47 \pm 0.01$ & $0.54 \pm 0.03$ & $0.65 \pm 0.05^{*}$ & $0.50 \pm 0.01$ & $0.52 \pm 0.01$ \\
\hline NEFA & $0.13 \pm 0.01$ & $0.10 \pm 0.02$ & $0.08 \pm 0.01 *$ & $0.12 \pm 0.03$ & $0.12 \pm 0.01$ \\
\hline Insulin & $22.3 \pm 1.7$ & $19.0 \pm 0.9$ & $17.7 \pm 1.1^{*}$ & $17.0 \pm 1.1^{*}$ & $13.6 \pm 1.2 *$ \\
\hline Glucose & $75.9 \pm 3.6$ & $83.6 \pm 3.9$ & $64.9 \pm 2.9^{*}$ & $70.6 \pm 1.5^{*}$ & $69.9 \pm 1.9 *$ \\
\hline BHBA & $4.29 \pm 0.31$ & $4.93 \pm 0.29$ & $3.90 \pm 0.21$ & $4.40 \pm 0.27$ & $3.23 \pm 0.45^{*}$ \\
\hline
\end{tabular}

Data are expressed as means \pm SEM. Asterisks indicate significant differences $(\mathrm{P}<0.05)$ versus day -7 . (NEFA, non-esterified fatty acids; TNF- $\alpha$, tumour necrosis factor- $\alpha$; BHBA, $\beta$-hydroxy butyric acid, rQUICKI, revised quantitative insulin sensitivity check index)

Table 2. Correlation coefficients among serum BHBA, TNF- $\alpha$, insulin, glucose, NEFA concentrations, and rQUICKI in cows $(n=30)$ on different days of periparturient period

\begin{tabular}{|c|c|c|c|c|c|c|}
\hline Day -7 & Adiponectin & rQUICKI & BHBA & TNF- $\alpha$ & Insulin & Glucose \\
\hline rQUICKI & 0.036 & & & & & \\
\hline BHBA & $-0.399 *$ & -0.167 & & & & \\
\hline TNF- $\alpha$ & $-0.509 * *$ & -0.143 & $-0.489 * *$ & & & \\
\hline Insulin & $-0.363^{*}$ & -0.278 & $0.838 * *$ & $-0.451 *$ & & \\
\hline Glucose & $-0.405^{*}$ & -0.352 & 0.028 & $0.692 * *$ & -0.055 & \\
\hline NEFA & $0.416^{*}$ & $-0.543^{* *}$ & $-0.375^{*}$ & -0.082 & -0.287 & 0.076 \\
\hline Day 0 & Adiponectin & rQUICKI & BHBA & TNF- $\alpha$ & Insulin & Glucose \\
\hline rQUICKI & $-0.373^{*}$ & & & & & \\
\hline BHBA & -0.103 & 0.008 & & & & \\
\hline TNF- $\alpha$ & 0.275 & 0.093 & 0.357 & & & \\
\hline Insulin & 0.065 & $-0.503 * *$ & $0.562 * *$ & 0.011 & & \\
\hline Glucose & -0.260 & -0.288 & -0.033 & -0.220 & -0.041 & \\
\hline NEFA & $0.550 * *$ & $-0.927 * *$ & -0.074 & -0.033 & $0.393 *$ & 0.087 \\
\hline Day 7 & Adiponectin & rQUICKI & BHBA & TNF- $\alpha$ & Insulin & Glucose \\
\hline rQUICKI & -0.245 & & & & & \\
\hline BHBA & -0.089 & $-0.627 * *$ & & & & \\
\hline TNF- $\alpha$ & -0.203 & -0.060 & -0.126 & & & \\
\hline Insulin & -0.279 & 0.266 & $0.598 * *$ & -0.006 & & \\
\hline Glucose & -0.334 & $-0.371 *$ & -0.196 & -0.225 & -0.005 & \\
\hline NEFA & $0.363^{*}$ & $-0.807 * *$ & $-0.596^{* *}$ & -0.138 & $-0.670^{* *}$ & 0.120 \\
\hline Day 14 & Adiponectin & rQUICKI & BHBA & TNF- $\alpha$ & Insulin & Glucose \\
\hline rQUICKI & $-0.362^{*}$ & & & & & \\
\hline BHBA & $0.674 * *$ & $-0.467 *$ & & & & \\
\hline TNF- $\alpha$ & -0.082 & -0.022 & 0.077 & & & \\
\hline Insulin & 0.128 & -0.283 & $0.669 * *$ & 0.223 & & \\
\hline Glucose & -0.011 & -0.074 & 0.011 & 0.038 & 0.075 & \\
\hline NEFA & $0.408 *$ & $-0.845^{* *}$ & $0.442^{*}$ & 0.060 & -0.117 & -0.115 \\
\hline Day 21 & Adiponectin & rQUICKI & BHBA & TNF- $\alpha$ & Insulin & Glucose \\
\hline rQUICKI & -0.220 & & & & & \\
\hline BHBA & 0.309 & -0.319 & & & & \\
\hline TNF- $\alpha$ & $-0.478 *$ & $0.720 * *$ & $-0.538 * *$ & & & \\
\hline Insulin & -0.186 & $-0.528 * *$ & $0.603^{* *}$ & $-0.604 * *$ & & \\
\hline Glucose & $-0.368 *$ & -0.212 & $0.423 *$ & $0.740 * *$ & $0.423^{*}$ & \\
\hline NEFA & $0.546^{* *}$ & $-0.480 * *$ & -0.178 & $-0.430 *$ & $-0.359 *$ & -0.254 \\
\hline
\end{tabular}

Asterisks indicate significant correlation between each parameter $(* \mathrm{P}<0.05, * * \mathrm{P}<0.01)$. (NEFA, non-esterified fatty acids; TNF- $\alpha$, tumour necrosis factor- $\alpha$; BHBA, $\beta$-hydroxy butyric acid, rQUICKI, revised quantitative insulin sensitivity check index) 


\section{Discussion}

Adiponectin is an adipokine secreted by adipose tissue which is reported to inhibit lypolysis and decrease insulin resistance (29). In our study, adiponectin levels increased significantly 21 days after parturition. Similar findings were also observed in previous reports $(18,25)$. In addition, Singh et al. (25) reported that not only serum adiponectin levels but also levels of adiponectin in fat tissue decreased around parturition, concluding that the drop in adiponectin level could be related to parturition-related hormonal changes or increased secretion of adiponectin into colostrum. Increased lipolysis and decreased lypogenesis around parturition causes elevation of blood NEFA levels (17). However, in our study we did not detect a significant increase in blood NEFA concentrations. Interestingly, adiponectin was positively correlated with serum NEFA levels during the study period. This finding is in contrast with other reports in which NEFA either did not correlate (18) or correlated negatively (26) with serum adiponectin levels in cattle. Similar negative correlations were also reported in earlier human studies, leading to the conclusion that a decrease in adiponectin levels is associated with increased lypolysis $(13,28)$. However, Bernstein et al. (1) reported that acute lowering of free fatty acids (FFA) results in decreased levels of circulating adiponectin. Similarly, increasing serum FFA levels by infusion of lipids resulted in increased adiponectin levels, which were positively correlated with FFA (27). Adiponectin is also demonstrated to increase clearance of FFA in mice, probably by increasing the uptake by skeletal muscle and/or by increasing FFA oxidation (5, 15). Singh et al. (25) demonstrated that increased adipocyte size is inversely related with adiponectin. It is well known that adipocyte sizes increase in fatty liver. Thus, on the basis of the relationship between the NEFA and adiponectin levels described in cattle and the ideal body condition scores identified in our study, we concluded that adiponectin might have an important role in decreasing blood NEFA levels, probably by mechanisms mentioned above.

The rQUICKI is a method developed for calculating insulin sensitivity by determining blood NEFA, insulin, and glucose concentrations (20). Holtenius and Holtenius (7) suggested that this method could also be used for calculating insulin sensitivity in cattle. Low index calculations indicate decreased insulin sensitivity. In our study, rQUIKCI levels showed a significant increase on day 7 postpartum when compared to the prepartum levels. Singh et al. (26) reported a positive correlation between rQUICKI and adiponectin, concluding that decreased adiponectin concentration around calving is related with insulin resistance required for facilitating nutrient partitioning towards the mammary gland. However, we detected negative correlations between rQUICKI and adiponectin on calving day and on day 14 postpartum. Adiponectin level is associated with decreased insulin sensitivity in mammals. Lemor et al. (14) reported that adiponectin sensitivity of adipocytes is reduced after calving, thus although the adiponectin level was elevated in our study, the decreased insulin sensitivity could be related to decreased adiponectin sensitivity.

TNF- $\alpha$ is a proinflamatory cytokine produced mainly by macrophages and by other cells like lymphocytes, Kupffer cells, and adipocytes (12). Levels of TNF- $\alpha$ are elevated in late pregnancy in humans (22) and the relationship between TNF- $\alpha$ and insulin resistance is well documented in humans (8) and cattle (19). Administration of recombinant bovine TNF- $\alpha$ to steers for 12 days resulted in increased insulin resistance (11). The level of TNF- $\alpha$ was also positively correlated with rQUICKI 21 days after calving, which is in accordance with the observations of other authors $(8,19)$. Elevated TNF- $\alpha$ concentration is also shown to cause a decrease in circulating adiponectin levels in humans (2). Similarly, in our study, adiponectin concentration was found to be decreased while TNF- $\alpha$ level was the highest on $7^{\text {th }}$ day before parturition, and this negative correlation was also observed 21 days after parturition, when TNF- $\alpha$ level decreased and adiponectin level increased.

In conclusion, periparturient serum level of adiponectin in cows was found to be negatively correlated with TNF- $\alpha$ concentration. Unexpectedly, our study demonstrated a positive correlation of adiponectin with NEFA and insulin resistance. Thus it can be concluded that in the cows with normal BCS around parturition and without severe NEB, adiponectin may act as a hormone which balances NEB and blood NEFA levels. In addition, we hypothesise that increased adipocyte size in cattle with high BCS in periparturient period may be responsible for higher NEFA levels due to decreased adiponectin concentration. However, further studies conducted on cattle with altered metabolic profiles are required to elucidate a relationship between these parameters.

Conflict of Interests Statement: The authors declare that they have no conflict of interests regarding the publication of this article.

Financial Disclosure Statement: This study was financially supported by the Research Fund of Uludag University (Grant no. KUAP(V)-2012/46).

Animal Rights Statement: This study was approved by the Uludag University Animal Research Local Ethics Committee.

\section{References}

1. Bernstein E.L., Koutkia P., Ljungquist K., Breu J., Canavan B., Grinspoon S.: Acute regulation of adiponectin by free fatty acids. Metabolism 2004, 53, 790-793. 
2. Bruun J.M., Lihn A.S.,Verdich C., Pedersen S.B., Toubro S., Astrup A., Richelsen B.: Regulation of adiponectin by adipose tissue-derived cytokines: in vivo and in vitro investigations in humans. Am J Physiol Endocrinol Metab 2003, 285, 527-533.

3. Eicher R., Liesegang A., Bouchard E., Tremblay A.: Influence of concentrate feeding frequency and intrinsic factors on diurnal variations of blood metabolites in dairy cows. Proc Am Assoc Bov Pract, Rome, 1998, 198-202.

4. Ferguson J.D., Galligan D.T., Thomsen N.: Principal descriptors of body condition score in Holstein cows. J Dairy Sci 1994, 77, 2695-2703.

5. Fruebis J., Tsao T.S., Javorschi S., Ebbets-Reed D., Erickson M.R., Yen F.T, Bihain B.E., Lodish H.F.: Proteolytic cleavage product of $30-\mathrm{kDa}$ adipocyte complement-related protein increases fatty acid oxidation in muscle and causes weight loss in mice. Proc Natl Acad Sci USA 2001, 98, 2005-2010.

6. Hayirli A.: The role of exogenous insulin in the complex of hepatic lipidosis and ketosis associated with insulin resistance phenomenon in postpartum dairy cattle. Vet Res Commun 2006, 30, 749-774.

7. Holtenius P., Holtenius K.: A model to estimate insulin sensitivity in dairy cows. Acta Vet Scand 2007, 49, 29-31.

8. Hotamisligil G.S., Shargill N.S., Spiegelman B.M.: Adipose expression of tumor necrosis factor- $\alpha$ : direct role in obesitylinked insulin resistance. Science 1993, 259, 87-91.

9. Kahn C.R.: Insulin resistance, insulin insensitivity, and insulin unresponsiveness: a necessary distinction. Metabolism 1978, 27, 1893-1902.

10. Komatsu T., Itoh F., Sakumoto R., Hodate K., Obara Y., Kushibiki S.: Changes in the gene expression of adiponectin and glucose transporter 12 (GLUT12) in lactating and non-lactating cows. Anim Sci J 2007, 78, 98-102.

11. Kushibiki S., Hodate K., Shingu H., Ueda Y., Mori Y., Itoh T., Yokomizo Y.: Effects of long-term administration of recombinant bovine tumor necrosis factor- $\alpha$ on glucose metabolism and growth hormone secretion in steers. Am J Vet Res 2001, 62, 794-798.

12. Kushibiki S.: Tumor necrosis factor- $\alpha$-induced inflammatory responses in cattle. Anim Sci J 2011, 82, 504-511.

13. Lavoie F., Frisch F., Brassard P., Normand-Lauzière F., Cyr D., Gagnon R., Drouin R., Baillargeon J.P., Carpentier A.C.: Relationship between total and high molecular weight and adiponectin levels and plasma nonesterified fatty acid tolerance during enhanced intravascular triacylglycerol lipolysis in men. J Clin Endocr Metab 2009, 94, 998-1004.

14. Lemor A., Hosseini A., Sauerwein H., Mielenz M.: Transition period-related changes in the abundance of the mRNAs of adiponectin and its receptors, of visfatin, and of fatty acid binding receptors in adipose tissue of high-yielding dairy cows. Domest Anim Endocrinol 2009, 37, 37-44.

15. Maeda N., Shimomura I., Kishida K., Nishizawa H., Matsuda M., Nagaretani H., Furuyama N., Kondo H., Takahashi M., Arita Y., Komuro R., Ouchi N., Kihara S., Tochino Y., Okutomi K., Horie M., Takeda S., Aoyama T., Funahashi T., Matsuzawa Y.: Diet-induced insulin resistance in mice lacking adiponectin/ACRP30. Nature Med 2002, 8, 731-737.

16. Mc Dowell G.H., Gooden J.M., Leenanuruksa D., Jois M., English A.W.: Effects of exogenous growth hormone on milk production and nutrient uptake by muscle and mammary tissues of dairy cows in mid-lactation. Aus J Biol Sci 1987, 40, 295-306.

17. McNamara J.P.: Lipid metabolism in adipose tissue during lactation: a model of a metabolic restricted-fed system. J Nutr 1994, 124, 1383-1391.
18. Ohtani Y.,Takahashi T., Sato K., Ardiyanti A., Song S.H., Sato R., Onda K., Wada Y., Obara Y., Suzuki K., Hagino A., Roh S.G., Katoh K.: Changes in circulating adiponectin and metabolic hormone concentrations during periparturient and lactation periods in Holstein dairy cows. Anim Sci J 2012, 83, 788-795.

19. Ohtsuka H., Koiwa M., Hitsugaya A., Kudo K., Hoshi F., Itoh N., Yokota H., Okada H., Kawamura S.: Relationship between serum TNF activity and insulin resistance in dairy cows affected with naturally occurring fatty liver. J Vet Med Sci 2001, 63, 1021-1025.

20. Perseghin G., Caumo A., Caloni M., Testolin G., Luzi L.: Incorporation of the fasting plasma FFA concentration into QUICKI improves its association with insulin sensitivity in nonobese individuals. J Clin Endocrinol Metab 2001, 86, 4776-4781.

21. Pravettoni D., Doll K., Hummel M., Cavallone E., Re M., Belloli A.G.: Insulin resistance and abomasal motility disorders in cows detected by use of abomaso-duodenal electromyography after surgical correction of left displaced abomasum. Am J Vet Res 2004, 65, 1319-1324.

22. Radaelli T., Uvena-Celebrezze J., Minium J., Huston-Presley L., Catalano P., Hauguel-De Mouzon S.: Maternal interleukin-6: marker of fetal growth and adiposity. J Soc Gynecol Investig 2006, 13, 53-57.

23. Sakai T., Hayakawa T., Hamakawa M., Ogura K., Kubo S.: Therapeutic effects of simultaneous use of glucose and insulin in ketotic dairy cows. J Dairy Sci 1993, 76, 109-114.

24. Sano H., Nakai M., Kondo T., Terashima Y.: Insulin responsiveness to glucose and tissue responsiveness to insulin in lactating, pregnant, and nonpregnant, nonlactating beef cows. J Anim Sci 1991, 69, 1122-1127.

25. Singh S.P., Häussler S., Heinz J.F., Akter S.H., Saremi B., Muller U., Rehage J., Dänicke S., Mielenz M., Sauerwein H.: Lactation driven dynamics of adiponectin supply from different fat depots to circulation in cows. Domest Anim Endocrinol 2014, $47,35-46$.

26. Singh S.P.,Häussler S., Heinz J.F., Saremi B., Mielenz B., Rehage J., Dänicke S., Mielenz M., Sauerwein H.: Supplementation with conjugated linoleic acids extends the adiponectin deficit during early lactation in dairy cows. Gen Comp Endocrinol 2014, 198, 13-21.

27. Staiger H., Tschritter O., Kausch C., Lammers R., Stumvoll M., Haring H.U.: Human serum adiponectin levels are not under short-term negative control by free fatty acids in vivo. Horm Metab Res 2002, 34, 601-603.

28. Weiss R., Dufour S., Groszmann A., Petersen K., Dziura J., Taksali S.E., Shulman G., Caprio S.: Low adiponectin levels in adolescent obesity: a marker of increased intramyocellular lipid accumulation. J Clin Endocrinol Metab 2003, 88, 2014-2018.

29. Yamauchi T., Kamon J., Waki H., Terauchi Y., Kubota N., Hara K., Mori Y., Ide T., Murakami K., Tsuboyama-Kasaoka N., Ezaki O., Akanuma Y., Gavrilova O., Vinson C., Reitman M.L., Kagechika H., Shudo K., Yoda M., Nakano Y., Tobe K., Nagai R., Kimura S., Tomita M., Froguel P., Kadowaki T.: The fat-derived hormone adiponectin reverses insulin resistance associated with both lipoatrophy and obesity. Nature Med 2001, 7, 941-946.

30. Yamauchi T., Kamon J., Minokoshi Y., Ito Y., Waki H., Uchida S., Yamashita S., Noda M., Kita S., Ueki K., Eto K., Akanuma Y., Froguel P., Foufelle F., Ferre P., Carling D., Kimura S., Nagai R., Kahn B.B., Kadowaki T.: Adiponectin stimulates glucose utilization and fatty-acid oxidation by activating AMP-activated protein kinase. Nature Med 2002, 8, 1288-1295. 